\title{
Choledochoduodenostomy for biliary drainage of malignant obstruction after failed endoscopic retrograde cholangiopancreatography
}

\author{
Voja Jovanovic MD, Christopher W Teshima MD MSc PhD FRCPC
}

\section{CASE PRESENTATION}

A 79-year-old woman presented with epigastric pain and jaundice, and had a bilirubin level of $291 \mu \mathrm{mol} / \mathrm{L}$. A computed tomography (CT) scan of the abdomen revealed an unresectable mass in the head of the pancreas, with resulting biliary obstruction. Endoscopic retrograde cholangiopancreatography (ERCP) was attempted but failed due to tumour ingrowth into the second part of the duodenum, which prevented access to the papilla. Endoscopic ultrasound (EUS) revealed the common bile duct (CBD) dilated to $1.5 \mathrm{~cm}$ proximal to the tumour. Using fluoroscopy and EUS guidance, the dilated CBD was accessed using a 19-gauge fine-needle aspiration needle, followed by cholangiogram, wire cannulation, balloon dilation and deployment of a fully covered $10 \mathrm{~mm} \times 4 \mathrm{~cm}$ biliary Wallflex (Boston Scientific, USA) stent from the CBD into the duodenal bulb, resulting in immediate drainage of bile (Figures 1 to 5). A $22 \mathrm{~mm} \times 60 \mathrm{~mm}$ uncovered duodenal Wallflex stent was also placed to relieve the duodenal obstruction. The serum bilirubin level gradually decreased to $15 \mu \mathrm{mol} / \mathrm{L}$ and remained normal at three months follow-up.

A second patient, a 68-year-old man with known metastatic pancreas adenocarcinoma diagnosed three months previously, presented with worsening abdominal pain and new-onset jaundice (bilirubin level $107 \mu \mathrm{mol} / \mathrm{L}$ ). CT revealed a $4.5 \mathrm{~cm}$ mass in the head of the pancreas encasing the CBD. ERCP failed due to inability to advance the wire through the tumour, despite successful cannulation. An attempt

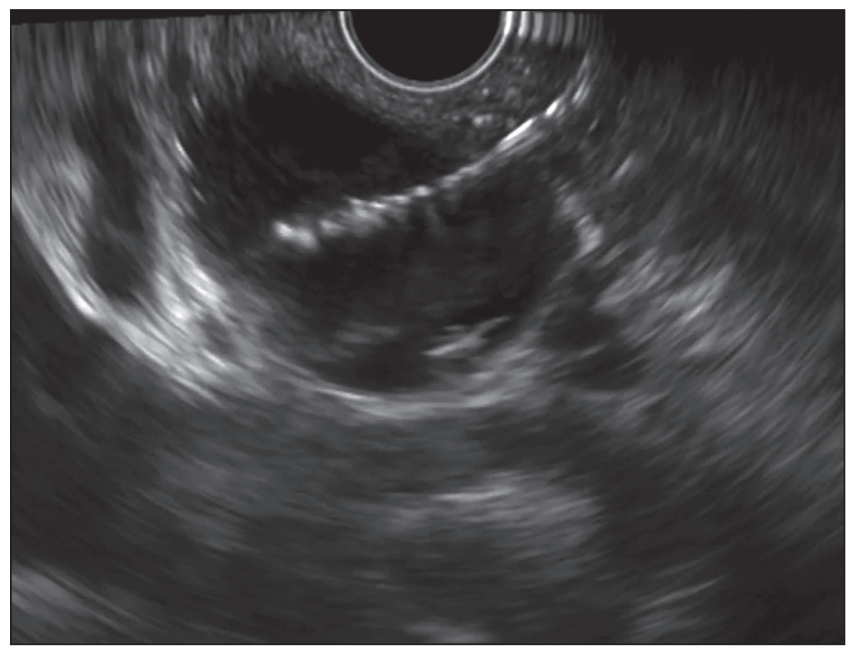

Figure 1) Endoscopic ultrasound-guided puncture and wire access to the common bile duct above the level of the tumour at EUS-guided rendezvous was abandoned after unsuccessful wire advancement due to complete obliteration of the CBD within the tumour. Under fluoroscopic and EUS guidance, a fully-covered $10 \mathrm{~mm}$ $\times 4 \mathrm{~cm}$ biliary Wallflex stent was then placed from the CBD into the duodenal bulb. His bilirubin level decreased to $48 \mu \mathrm{mol} / \mathrm{L}$ four days postprocedure and to $4 \mu \mathrm{mol} / \mathrm{L}$ at two months follow-up. No early or late complications occurred in either case.

\section{DISCUSSION}

Percutaneous transhepatic cholangiography (PTC) has been the traditional salvage option after failed ERCP in malignant distal biliary obstruction. Recently, EUS-guided biliary drainage (EUS-BD) has been developed as an alternative method. EUS-BD consists of an EUSguided rendezvous procedure followed by conversion to ERCP, or direct transmural drainage either in the form of choledochoduodenostomy or

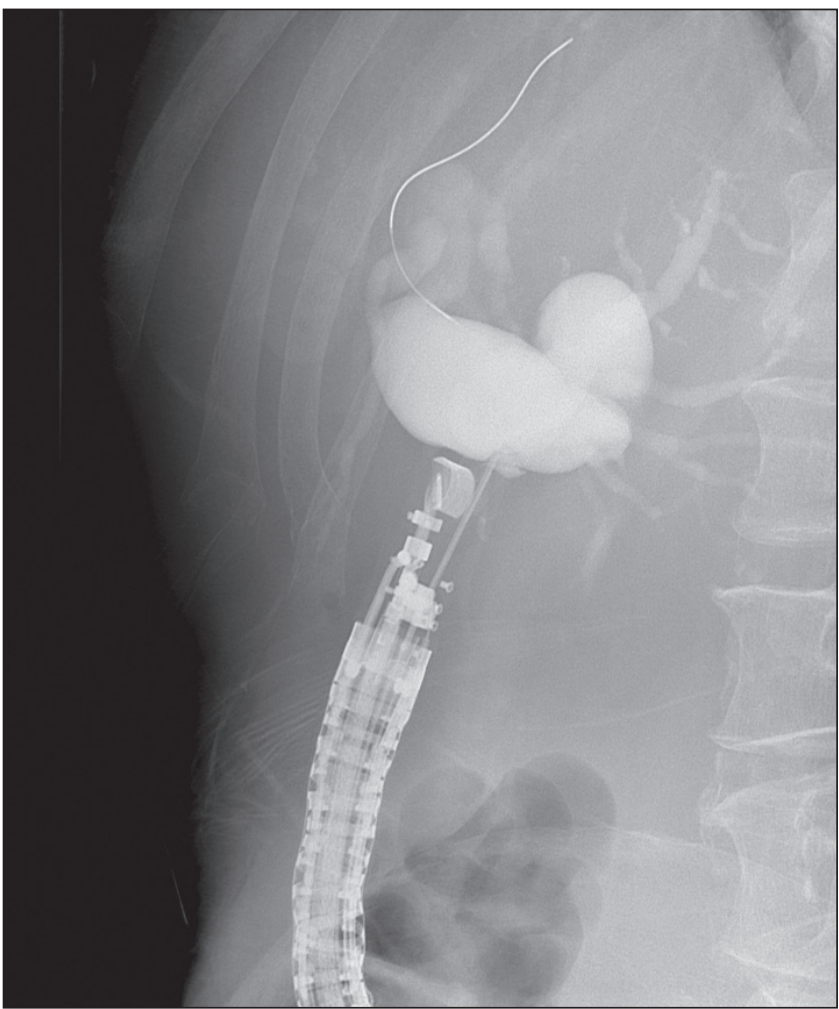

Figure 2) Cholangiogram revealing the obstructed bile duct

Division of Gastroenterology, University of Alberta, Edmonton, Alberta

Correspondence: Dr Christopher W Teshima, University of Alberta Hospital, 2-28 Zeidler Ledcor Centre, Edmonton, Alberta T6G 2 X8.

Telephone 780-248-1673, fax 780-492-9416, e-mail teshima@ualberta.ca

Received for publication January 8, 2015. Accepted January 12, 2015 


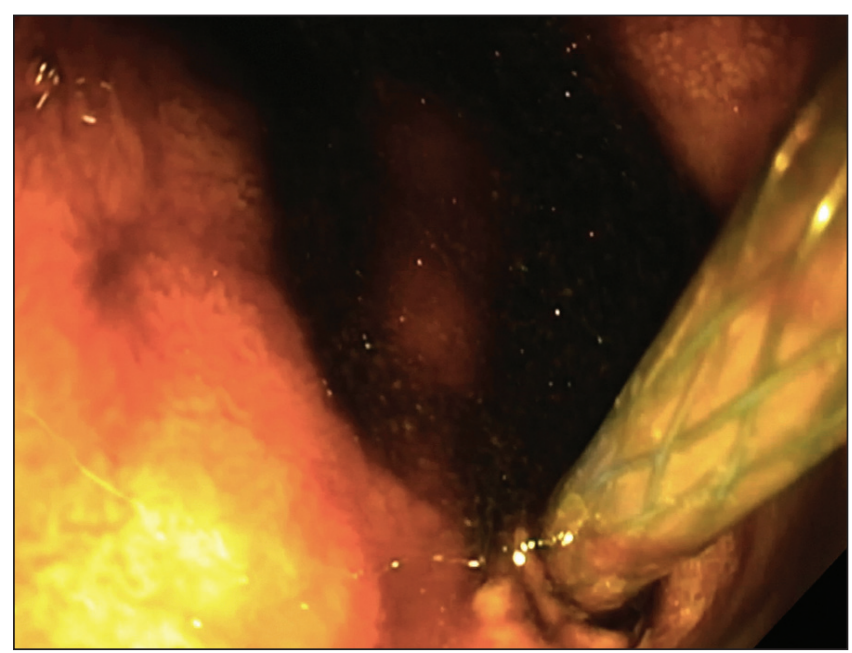

Figure 3) Stent deployment with direct endoscopic visualization

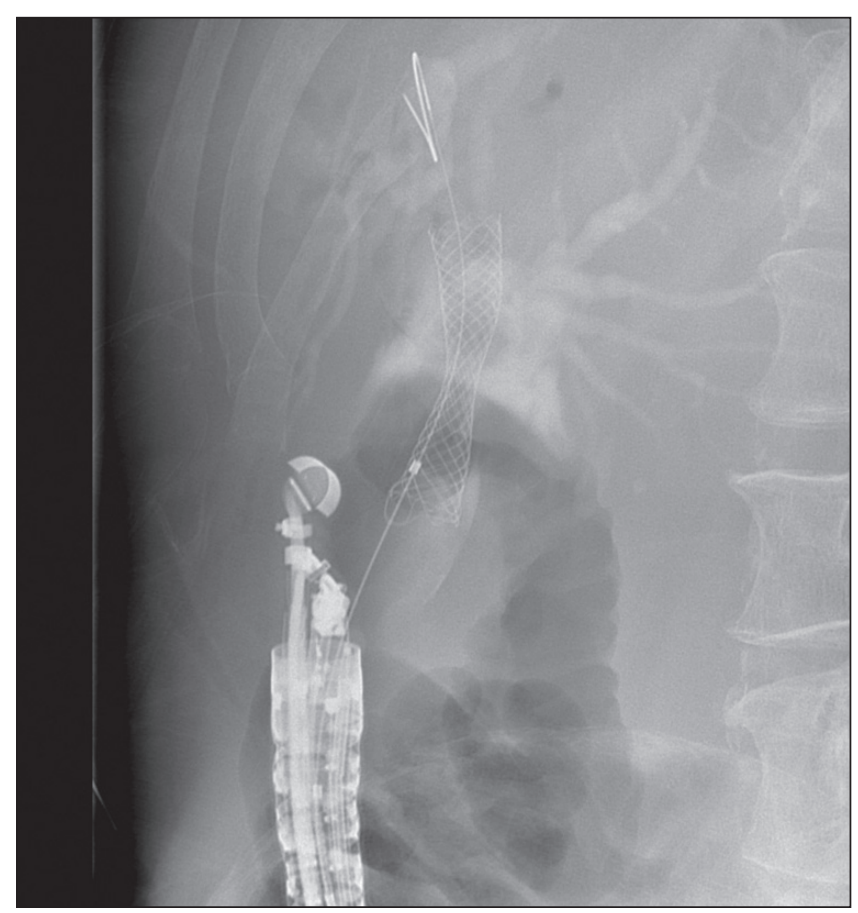

Figure 4) Stent deployment under fluoroscopic guidance

hepaticogastrostomy. Advantages over PTC include the ability to perform it immediately following failed ERCP and lack of an external drain. There are limited data for this novel procedure; however, early series suggest similar efficacy and safety compared with PTC (1). The largest study reports equivalent outcomes between rendezvous and direct transluminal EUS-BD techniques (2). The primary reasons for pursuing transmural drainage are the inability to access

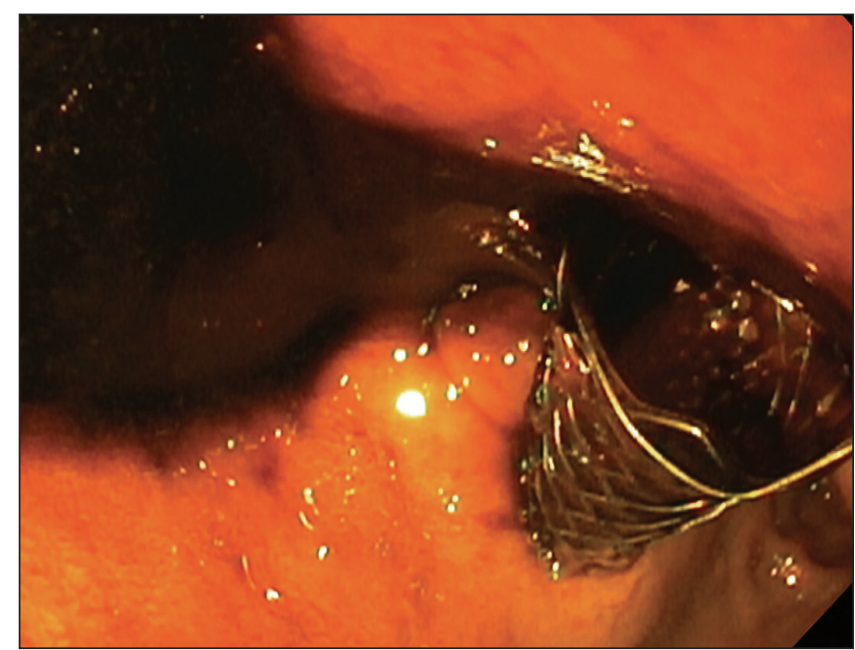

Figure 5) Biliary drainage via covered stent into duodenal bulb

the ampulla or failure to traverse a malignant biliary stricture (3). The overall success rate of EUS-BD after failed ERCP may be as high as $91 \%(4)$, with a complication rate of $15 \%$, including pneumoperitoneum, bleeding, stent migration and, occasionally, bile peritonitis. When a duodenal stent has been placed for luminal tumour invasion, EUS-guided transmural drainage may result in higher stent patency rates compared with traditional transpapillary drainage (5). The exact role of transmural biliary drainage remains undefined and is an area of ongoing research.

EUS-guided choledochoduodenostomy is a viable alternative after failed ERCP for malignant biliary obstruction, although it should be performed at expert referral centres.

DISCLOSURES: The authors have no financial disclosures or potential conflicts of interest to declare.

\section{REFERENCES}

1. Artifon E, Aparicio D, Paione JB, et al. Biliary drainage in patients with unresectable, malignant obstruction where ERCP fails: Endoscopic ultrasonography-guided choledochoduodenostomy versus percutaneous drainage. J Clin Gastroenterol 2012;46:768-74.

2. Khashab MA, Valeshabad AK, Modayil R, et al. EUS-guided biliary drainage by using a standardized approach for malignant biliary obstruction: Rendezvous versus direct transluminal techniques. Gastrointest Endosc 2013;78:734-41.

3. Sarkaria S, Sundararajan S, Kahakeh M. Endoscopic ultrasonographic access and drainage of the common bile duct. Gastrointest Endoscopy Clin N Am 2013;23:435-52.

4. Hara K, Yamao K, Hijioka S, et al. Prospective clinical study of endoscopic ultrasound-guided choledochoduodenostomy with direct metallic stent placement using a forward-viewing echoendoscope. Endoscopy 2013;45:392-6.

5. Hamada T, Isayama H, Nakai Y, et al. Transmural biliary drainage can be an alternative to transpapillary drainage in patients with an indwelling duodenal stent. Dig Dis Sci 2014;59:1931-8. 


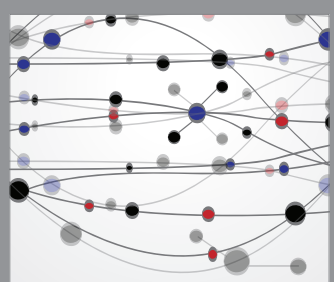

The Scientific World Journal
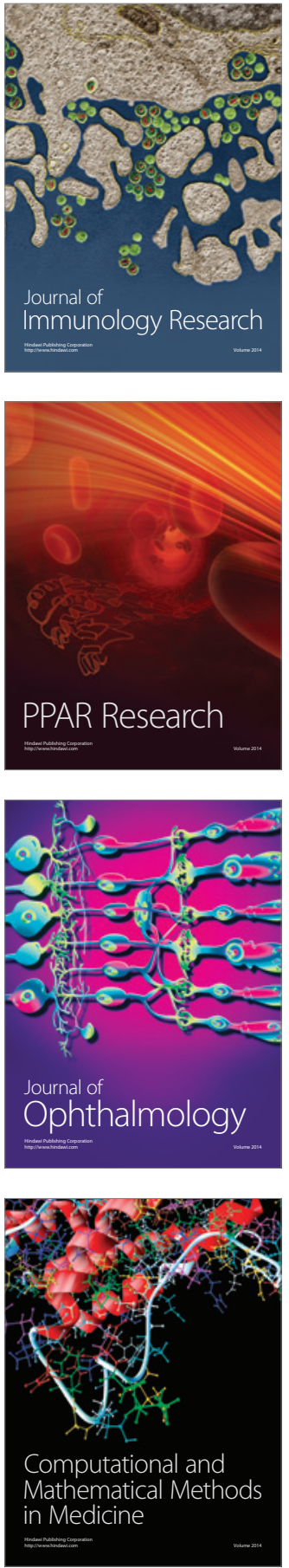

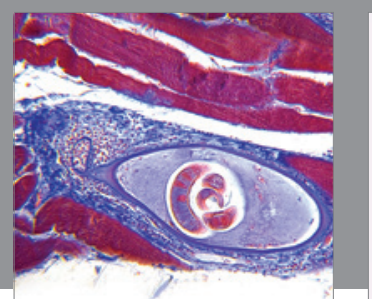

Gastroenterology Research and Practice

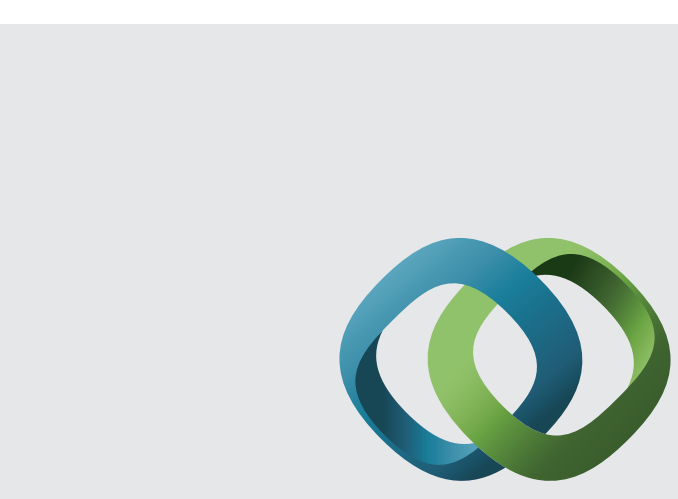

\section{Hindawi}

Submit your manuscripts at

http://www.hindawi.com
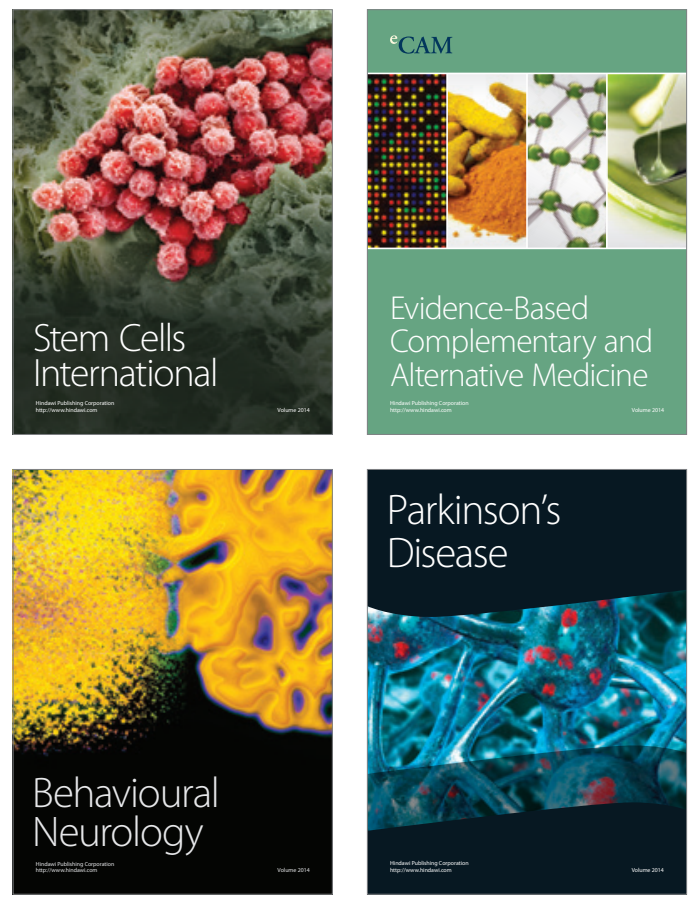
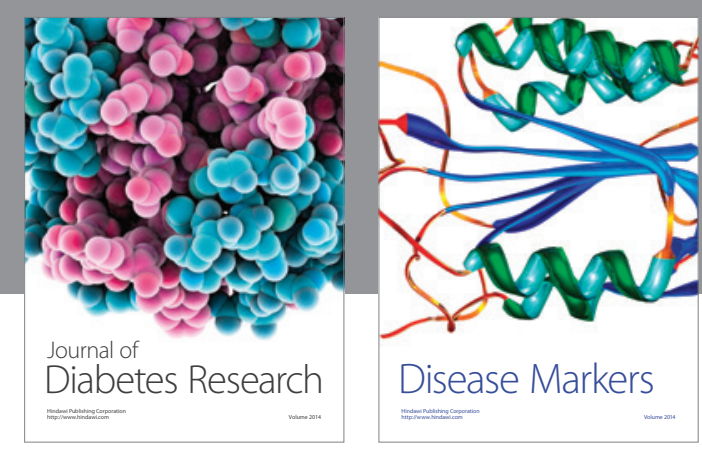

Disease Markers
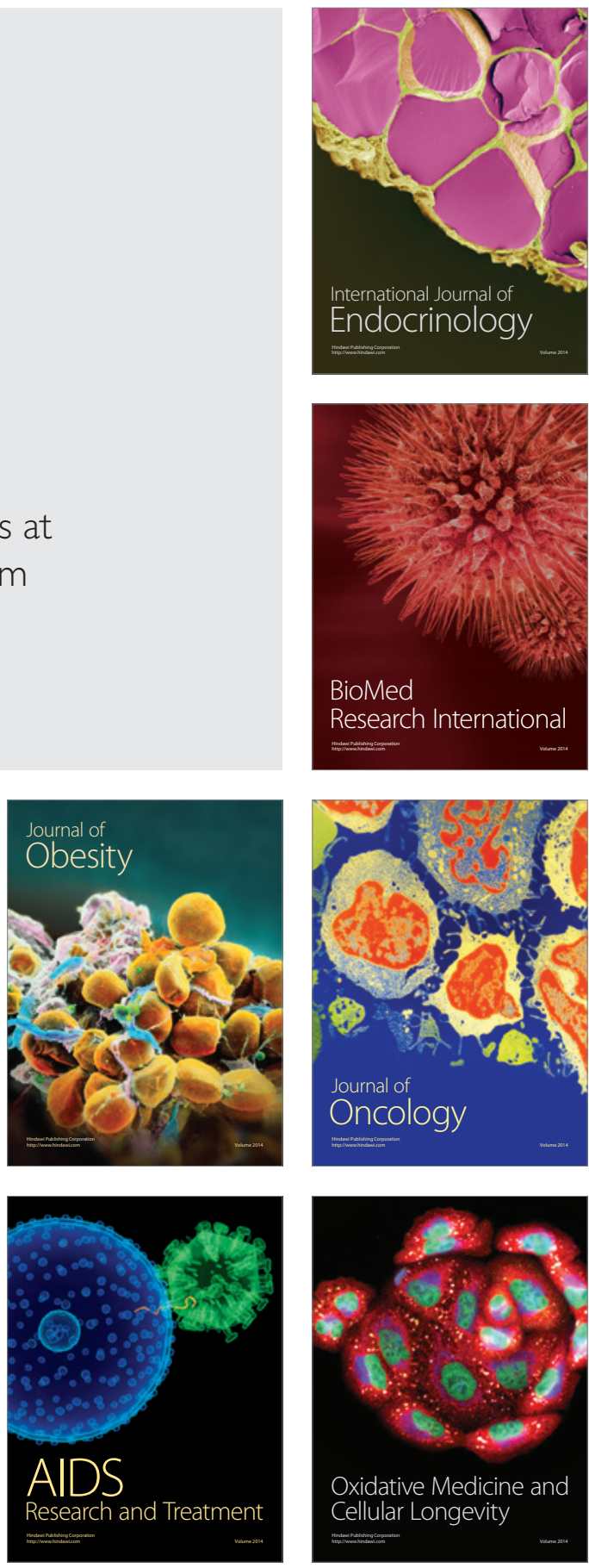